\title{
GAMBARAN PENERAPAN PELAYANAN FARMASI KLINIK DI PUSKESMAS
}

\author{
Nur Rasdianah ${ }^{1}$, Faramita Hiola ${ }^{2}$ \\ 1,2 Jurusan Farmasi, Fakultas Olahraga dan Kesehatan, Universitas Negeri Gorontalo Email : \\ nr.apoteker@gmail.com
}

\begin{abstract}
Pharmacy services are part of the pharmaceutical service standards at the puskesmas, aiming to improve therapeutic outcomes and ensure the patient's quality of life. The study aimed to determine the suitability of 7 aspects of pharmaceutical services with pharmaceutical service standards in the application of clinical pharmacy at the puskesmas. This research is an observational study using a survey method. The study was conducted at 31 Puskesmas in Bone Bolango and Pohuwato districts, Gorontalo Province, in May-August 2021. The pharmaceutical staff in charge of pharmaceutical services is the population in this study. The total sampling technique was used in sample selection. This research instrument is a checklist compiled based on pharmaceutical service standards at the puskesmas - collected data utilizing observation and interviews with respondents. Did analysis descriptively. The results showed that assessment and prescription services and drug information services were suitable, while the other five elements were poor.
\end{abstract}

\section{Keywords : Pharmacy services, Puskesmas}

\section{PENDAHULUAN}

Pelayanan kesehatan yang diperoleh seorang pasien yang datang berobat pada fasilitas kesehatan diantaranya adalah pelayanan medis yang diberikan oleh dokter dan layanan kefarmasian yang diberikan oleh tenaga professional apoteker. Pada umumnya tenaga kefamasian merupakan tenaga kesehatan terakhir yang akan berinteraksi dengan pasien dalam suatu siklus pelayanan kesehatan di puskesmas. Pemberian obat atau sediaan farmasi yang disertai informasi pendukung merupakan layanan farmasi yang dimaksudkan untuk keberhasilan terapi pasien dan meminimalkan timbulnya resiko penggunaan obat yang tidak diinginkan.

Secara bertahap pelayanan kefarmasian di fasilitas kesehatan dasar sudah dimulai diterapkan dan berikan oleh tenaga kefarmasian (Blondal et al., 2017; Lui et al., 2017). Tenaga farmasi memberikan layanan di puskesmas berupa pelayanan manajemen obat dan farmasi klinik. Dalam penyajian farmasi klinik terdapat 7 dimensi pelayanan yang dapat diberikan di puskesmas oleh tenaga farmasi sesuai ketetapan peraturan yang berlaku yaitu: Kajian dan layanan resep, Pemberian Informasi Obat, Konseling, Ronde Pasien (khusus puskesmas rawat inap), Pemantauan Terapi Obat, Evaluasi Penggunaan Obat, dan Monitoring Efek
Samping Obat. Penerapan pelayanan ini dalam pelaksanaannya harus mengacuh pada Standar Pelayanan Kefarmasian yang tercantum dalam Peraturan Menteri Kesehatan RI Nomor 74 Tahun 2016. Pada implementasi pelayanan kefarmasian diperlukan pemantauan dan pengontrolan secara berkala sebagai upaya untuk menjamin kualitas pelayanan kefarmasian agar dapat terlaksana dengan sempurna. Kegiatan ini bertujuan untuk memperoleh gambaran situasi penerapan pelayanan kefarmasian sebagai dasar perbaikan pelayanan kefarmasian Puskesmas di masa mendatang (Kemenkes, 2017).

Berdasarkan laporan kinerja dinas kesehatan provinsi Gorontalo, capaian kinerja pelayanan kefarmasian di puskesmas dan rumah sakit masih dibawah 50\% dari target yang ditetapkan oleh dinas kesehatan propinsi Gorontalo pada tahun 2019.

Ketidaktercapaian disebabkan oleh berbagai hambatan dan kendala (Dinkes Propinsi, 2019). Untuk melihat perkembangan pelaksanaan layanan kefarmasian di fasilitas kesehatan dasar yang ada di propinsi Gorontalo saat ini maka perlu dilakukan sebuah studi, yang diharapkan dapat mengukur kondisi layanan farmasi saat ini. Kabupaten Bone Bolango dan Kabupaten Pohuwato merupakan 2 kabupaten yang 
berada di wilayah propinsi Gorontalo. Pemilihan lokasi didasarkan pada kabupaten yang terdekat dan terjauh dari ibukota propinsi Gorontalo. Berdasarkan data dari Dinas Kesehatan Propinsi Gorontalo total puskesmas yang tersebar di 2 kabupaten tersebut sebanyak 36 puskesmas. Dari studi ini diharapkan implementasi pelayanan farmasi klinik yang dilakukan oleh tenaga kefarmasian sesuai dengan standar pelayanan yang berlaku di puskesmas.

\section{METODE}

Jenis penelitian adalah deskriptif kuantitatif dengan cara survey. Penelitian dilakukan pada fasilitas pelayanan kesehatan dasar atau Puskesmas yang tersebar di Kabupaten Bone Bolango dan Pohuwato Propinsi Gorontalo pada bulan Mei-Agustus 2021. Apoteker dan atau tenaga teknis kefarmasian yang menjadi penanggung jawab pada bagian pelayanan farmasi di Puskesmas merupakan populasi dalam penelitian ini. Seluruh populasi merupakan sampel penelitian ini.

Total jumlah puskesmas yang tersebar di dua kabupaten sebanyak 36 puskesmas, dan sebanyak 31 Tenaga kefarmasian yang berasal dari 31 puskesmas bersedia mengikuti penelitian dan 5 puskesmas tidak bersedia Alat yang digunakan berupa ceklist yang berisi aspek-aspek layanan farmasi yang didesain menurut standar pelayanan farmasi puskesmas. Penerapan 7 aspek pelaksanaan layanan farmasi klinik menjadi acuan penerapan penyelenggaraan pelayanan kefarmasian di tingkat puskesmas. Instrumen ceklist kegiatan diisi langsung oleh responden penelitian. Kemudian verifikasi oleh peneliti dengan cara menanyakan kembali kepada responden.

Data hasil penelitian kemudian diolah dengan cara mengitung bobot dari setiap pernyataan yang diberikan oleh responden. Bobot nilai 1 untuk pernyataan "ya:, dan bobot nilai 0 untuk penyataan "tidak". Penerapan standar pelayanan farmasi dengan total bobot $\geq 86$ dikatakan "baik", total bobot antara 65-85 dikatakan "sedang" dan total bobot <65 dikatakan "kurang". Data yang diperoleh kemudian dianalisis secara deskriptif.

\section{HASIL}

Berdasarkan hasil studi diperoleh profil jenis puskesmas dan tenaga kefarmasian dari seluruh puskesmas yang tersebar di kabupaten Bone Bolango dan Pohuwato.

Tabel 1. Karakteristik Puskesmas dan Tenaga Kefarmasian

\begin{tabular}{|c|c|c|c|}
\hline Karakteristik & & $n=31$ & $\%$ \\
\hline \multirow{3}{*}{$\begin{array}{l}\text { Jenis } \\
\text { Puskesmas }\end{array}$} & & & \\
\hline & $\begin{array}{l}\text { Non Rawat } \\
\text { Inap }\end{array}$ & 25 & 80,65 \\
\hline & Rawat Inap & 6 & 19.35 \\
\hline \multirow{3}{*}{$\begin{array}{l}\text { Tenaga } \\
\text { Kefarmasian }\end{array}$} & & & \\
\hline & Apoteker & 7 & 22.58 \\
\hline & $\mathrm{TTK}^{*}$ & 24 & 77.42 \\
\hline
\end{tabular}

*Tenaga Tekhnis Kefarmasian

Berdasarkan tabel 1, dari 31 puskesmas, terdapat 25 puskesmas non rawat inap dan 6 rawat inap. Proporsi tenaga kefarmasian yang bertanggung jawab dalam pelayanan farmasi di puskesmas didominasi oleh tenaga teknis kefarmasian. sebanyak $77.42 \%$ dan tenaga apoteker sebanyak $22.58 \%$.

Tabel 2. Profil Kegiatan layanan Farmasi Klinik yang dilakukan

\begin{tabular}{|c|c|c|}
\hline \multirow[t]{2}{*}{ Aspek kegiatan } & \multicolumn{2}{|c|}{$\begin{array}{l}\text { Pelayanan } \\
\text { Klinik }(n=31)\end{array}$} \\
\hline & Ada (\%) & Tidak (\%) \\
\hline $\begin{array}{l}\text { Kajian dan layanan } \\
\text { resep }\end{array}$ & 86.91 & 13.39 \\
\hline $\begin{array}{l}\text { Pemberian informasi } \\
\text { obat }\end{array}$ & 80.64 & 19.36 \\
\hline Konseling & 58.06 & 41.94 \\
\hline Ronde * & 44.44 & 55.56 \\
\hline $\begin{array}{l}\text { Monitoring } \quad \text { efek } \\
\text { samping obat }\end{array}$ & 21.33 & 78.67 \\
\hline Pemantauan terapi obat & 53.22 & 46.78 \\
\hline $\begin{array}{l}\text { Evaluasi Penggunaan } \\
\text { Obat }\end{array}$ & 48.39 & 51.61 \\
\hline $\begin{array}{l}\text { *Puskesmas rawat inap } \\
\text { Berdasarkan tabel } \\
\text { aspek dalam pelay } \\
\text { dilakukan di sebagi } \\
\text { Kesesuaian dengan } \\
\text { layanan farmasi terbe } \\
\text { pada dimensi Kajian r } \\
\text { dan sebesar 80, } \\
\text { Pemberian Informasi } \\
\text { kegiatan yang paling s } \\
\text { monitoring efek samp } \\
21.33 \% \text {. }\end{array}$ & $\begin{array}{l}2 \text { diketah } \\
\text { nan farn } \\
n \text { besar } \\
\text { standar } \\
\text { ar seban } \\
\text { sep dan la } \\
4 \% \text { pad } \\
\text { Obat } \\
\text { dikit dilak } \\
\text { ng obat y }\end{array}$ & $\begin{array}{l}\text { bahwa } 7 \\
\text { si klinik } \\
\text { uskesmas. } \\
\text { penerapan } \\
\text { k } 86,91 \% \\
\text { anan resep } \\
\text { kategori } \\
\text { Sedangkan } \\
\text { kan adalah } \\
\text { tu sebesar }\end{array}$ \\
\hline
\end{tabular}




\section{PEMBAHASAN}

Pekerjaan kefarmasian dilakukan oleh tenaga farmasi baik apoteker ataupun tenaga tehnis kefarmasian dalam implementasi pelayanan kefarmasian. Pelayanan yang diberikan agar masyarakat memperoleh sediaan farmasi yang berkhasiat, bermutu dan aman. Selain itu masyarakat juga memdapatkan layanan jasa farmasi yang memuaskan. Pelayanan farmasi seharusnya dilakukan oleh apoteker namun karena keterbatasan tenaga yang tersedia, maka sebagain besar tenaga farmasi yang ada di puskesmas adalah tenaga teknis kefarmasian. Karena keterbatasan jumlah tenaga apoteker yang bekerja pada puskesmas, maka puskesmas yang tidak memilki apoteker dapat tetap menjalankan pelayanan kefarmasian secara terbatas dengan pengawasan apoteker sesuai dengan Peraturan Pemerintah No. 26 tahun 2020 meliputi Pengkajian dan pelayanan resep, Pelayanan informasi obat dan Monitoring efek samping obat (Kemenkes RI, 2020). Apoteker yang bekerja pada fasilitas kesehatan dasar seharusnya sudah memberikan pelayanan farmasi klinis secara penuh, namun ternyata belum berjalan sesuai harapan, Menurut beberapa studi menunjukkan penerapan pelayanan klinis secara komprehensif oleh apoteker puskesmas masih rendah (Susyanty et al., 2020). Ini disebabkan karena jumlah tenaga farmasi yang tersedia masih kurang umumnya hanya 1 tenaga farmasi disetiap puskesmas sehingga beban kerja seorang tenaga farmasi lebih berat untuk dapat melakukan seluruh kegiatan layanan farmasi klinik.

Aspek pengkajian dan pelayanan resep telah dilaksanakan oleh tenaga kefarmasian sebesar $86,91 \%$. Tenaga kefarmasian telah melakukan pemeriksaan kelengkapan keabsahan resep berupa persyaratan administrasi yang terdiri dari identitas pasien, identitas obat dan identitas dokter. Kegiatan pemeriksaan keabsahan resep pada identitas pasien yang biasanya luput dari pemeriksaan adalah berat badan pasien. Pemeriksaan indentitas dokter yang tidak dilakukan sepenuhnya adalah nama dokter, dengan alasan semua resep berasal dari dokter puskesmas tersebut, dan umumnya puskesmas hanya memiliki satu dokter. Pada pemeriksaan farmasetik yang jarang dilakukan adalah stabilitas obat dan ketersediaan, sedangkan pada pertimbangan klinis yang jarang dilakukan adalah efek adiktif dan kontra indikasi. Keterbatasan waktu dan tenaga apoteker yang tersedia disetiap puskesmas menyebabkan pertimbangan klinik dalam pelayanan resep belum dilakukan disetiap puskesmas. Penyerahan obat adalah tahapan akhir pada aspek layanan resep. Penyerahan obat dirangkaian dengan pemberian informasi kepada pasien atau keluarga pasien yang terdiri dari informasi tentang dosis obat, aturan pakai obat, durasi dan frekuensi penggunaan obat, dan cara perlakuan obat dalam penyimpanan, serta konseling sesuai kebutuhan pasien. Pada aspek ini, informasi tentang kontraindikasi belum sepenuhnya dilakukan oleh tenaga kefarmasian.

Aspek Pelayanan Informasi Obat berdasarkan kesesuaian dengan standar pelayanan sebesar $80,64 \%$. Salah satu bagian dari pelayanan informasi obat yang sudah dilakukan yaitu memenuhi kebutuhan informasi bagi pasien atau keluarganya. Sedangkan untuk pemberian informasi obat kepada tenaga kesehatan lain terbatas pada permintaan dari tenaga kesehatan lain dilingkup puskesmas. Ketersediaan media PIO sebagian besar berupa poster dan label obat sedangkan ketersedian buletin dan majalah untuk mendukung pelaksanaan PIO sangat minim. Ketersedian tempat dan dukungan pustaka dalam melaksanakan PIO merupakan hambatan lain dalam pelaksanaannya.

Aspek Konseling merupakan aspek yang harus dilakukan oleh apoteker, namun ketersediaan tenaga apoteker di Puskesmas tidak merata. Pelaksanaan konseling berdasarkan kesesuaian dengan standar pelayanan kefarmasian puskesmas sebesar $58,06 \%$. Dari seluruh puskesmas yang diteliti hanya terdapat 7 puskesmas yang memiliki apoteker, selebihnya ditangani oleh tenaga teknis kefarmasian yang pastinya memiliki wewenang dan keterbatasan dalam melakukan konseling kepada pasien. Ruang konseling hampir tidak tersedia disetiap puskesmas. Pelaksanaan konseling dilakukan di ruang penyerahan obat. Konseling diberikan agar pasien atau keluarga pasien mengetahui tentang tujuan pengobatan, lama 
pengobatan, tanda toksis, efek samping, dan cara penyimpanan (Kemenkes, 2017). Studi menunjukkan bahwa terdapat peningkatan kepatuhan penggunaan obat pada pasien yang mendapat layanan konseling dari apoteker (Dewanti et al., 2015; Rasdianah et al., 2020).

Kesesuaian aspek Ronde/Visite dilakukan tenaga kefarmasian pada puskesmas rawat inap sebesar 58,06\%. Visite dilakukan bersama tim dokter dan tenaga kesehatan lain. Keterbatasan tenaga kefarmasian menyebabkan visite tidak berjalan sepeuhnya, selain itu lama rawat inap pada pasien puskesmas tergolong singkat. Penyerahan obat dilakukan melalui perawat ruangan. Hasil penelitian yang dilakukan oleh Dianita (2017) yang menunjukkan bahwa ketersediaan sarana dan prasarana yang tidak memadai dapat mengakibatkan ronde/visite tidak sepenuhnya dapat terlaksana (Dianita et al., 2017).

Pelaksanaan aspek monitoring efek samping obat hanya sebesar $21.33 \%$. Berbagai keterbatasan yang dimiliki oleh tenaga kefarmasian menyebabkan kegiatan monitoring tidak dilakukan. Selain itu partisipasi pasien untuk melaporkan secara mandiri bila mengalami efek samping ketika menggunakan obat tidak ada. Pemantauan terhadap efek samping obat adalah suatu upaya untuk memonitor keamanan obat setelah obat tersedia dipasaran. Kegiatan pemantauan ini dilakukan berkesinambungan dengan maksud agar evaluasi aspek efikasi, keamanan dan mutu yang telah dilakukan sebelum suatu obat yang sudah beredar tetap terjamin.

Aspek monitoring terapi obat yang sesuai dengan standar pelayanan sebesar $53,22 \%$. Pemtauan terapi obat di puskesmas belum berjalan sepenuhnya. Kendala ketersediaan tenaga kefarmasian disetiap puskesmas sangat terbatas sehingga pemantauan tidak dapat dilakukan pada pasien. Peningkatkan efektivitas terapi dan meminimalkan reaksi obat yang tidak dikehendaki merupakan tujuan dilakukannya monitoring terapi obat. Timbulnya interaksi obat dapat diatasi dengan melakukan prioritas monitoring terapi penggunaan obat berdasarkan jenis obat, jenis dan komplikasi penyakit. Untuk mengetahui tingkat keberhasilan dan kegagalan dari penggunaan obat maka pemantauan terapi obat harus dilakukan secara berkesinambungan dan di evaluasi secara berkala. Studi lain yang dilakukan oleh beberapa peneliti menunjukkan bahwa problem terkait obat yang kerap ditemukan antara lain terdapat kontraindikasi antara obat dengan kondisi pasien, cara pemberian yang salah, jumlah dosis yang tidak memenuhi dosis terapeutik dan timbulnya interaksi obat. Pada umumnya masalah terkait obat banyak dialami oleh pasien geriatrik (Farias et al., 2016; Hailu et al., 2020).

Aspek evaluasi penggunaan obat yang sesuai dengan standar pelayanan farmasi klinik sebesar 48,39\%. Evaluasi yang dilakukan oleh apoteker dan TTK di puskesmas pada penelitian ini terbatas pada penguunaan obat untuk pasien TBC, diabetes, dan hipertensi. Pelaksanaan dimensi evaluasi penggunaan obat masih sulit untuk dilakukan karena berbagai hambatan baik tenaga maupun waktu. Kegiatan evaluasi penggunaan seharusnya dilakukan secara berkala untuk memastikan pola penggunaan obat dan evaluasi penggunaannya untuk kasus tertentu.

Dari semua aspek pelayanan farmasi klinik di puskesmas, sistem dokumentasi atau pencatatan setiap kegiatan tidak tertata dan tersimpan dengan baik, sehingga penelusuran bukti kegiatan sulit dilakukan, diharapkan sistem pendokumentasian dimasa yang akan datang lebih teratur dan tertata rapi.

\section{KESIMPULAN}

Penerapan layanan farmasi klinik yang sesuai dengan standar pelayanan kefarmasian puskesmas yang termasuk pada kategori baik adalah aspek telaah resep dan pelayanan resep, aspek penyajian informasi obat. Sedangkan 5 aspek lainnya masih pada kategori kurang. Oleh karena itu pelaksanaan pelayanan farmasi klinik di puskesmas perlu mendapat perhatian dan dibutuhkan upaya bersama dalam mencapai tujuan tersebut.

\section{Ucapan Terima Kasih}

Seluruh Pihak Puskesmas dan Tenaga Kefarmasian di Propinsi Gorontalo, yang telah membantu jalannya penelitian ini. Terima kasih juga disampaikan kepada pihak Lembaga Penelitian dan Pengabdian kepada Masyarakat UNG atas bantuan dananya. 


\section{Pendanaan}

Penelitian ini menggunakan dana bantuan dari Lembaga Penelitian dan Pengabdian Masyarakat Universtas Negeri Gorontalo tahun 2021

\section{Konflik kepentingan}

Pada penelitian ini tidak terdapat konflik kepentingan.

\section{DAFTAR PUSTAKA}

Blondal, A.B., Sporrong, S.K., Almarsdottir, A.B., $2017 . \quad$ Introducing Pharmaceutical Care to Primary Care in Iceland-An Action Research Study. Pharm. J. Pharm. Educ. Pract. 5 , 23. https://doi.org/10.3390/pharmacy502 0023

Dewanti, S.W., Andrajati, R., Supardi, S., 2015. Pengaruh Konseling dan Leaflet terhadap Efikasi Diri, Kepatuhan Minum Obat, dan Tekanan Darah Pasien Hipertensi di Dua Puskesmas Kota Depok. J. Kefarmasian Indones. 33-40. https://doi.org/10.22435/jki.v5i1.347 2

Dianita, P.S., Kusuma, T.M., Septianingrum, N.M.A.N., 2017. Evaluasi penerapan standar pelayanan kefarmasian di puskesmas kabupaten Magelang berdasarkan Permenkes RI no. 74 tahun 2016. URECOL 125-134.

Dinkes Propinsi, P.K. dan A., 2019. Laporan Kinerja Satker Program Kefarmasian dan Alkes Dinas Kesehatan Propinsi Gorontalo.

Farias, T.F., Aguiar, K. da S., Rotta, I., Belletti, K.M. da S., Carlotto, J., 2016. Implementing a clinical pharmacy service in hematology. Einstein Sao Paulo Braz. 14, 384390. https://doi.org/10.1590/S167945082016AO3667

Hailu, B.Y., Berhe, D.F., Gudina, E.K., Gidey, K., Getachew, M., 2020. Drug related problems in admitted geriatric patients: the impact of clinical pharmacist interventions. BMC Geriatr. 20, 13. https://doi.org/10.1186/s12877-0201413-7

Kemenkes, 2017. Peraturan Menteri Kesehatan Republik Indonesia No.74 Tahun 2016 tentang Standar Pelayanan Kefarmasian di Puskesmas.

Kemenkes RI, 2020. Peraturan Menteri Kesehatan RI No. 25 Tahun 2020 tentang Standar Pelayanan Kefarmasian di Puskesmas.

Lui, E., Ha, R., Truong, C., 2017. Applying the pharmaceutical care model to assess pharmacist services in a primary care setting. Can. Pharm. J. CPJ 150, 90-93. https://doi.org/10.1177/17151635176 90538

Rasdianah, N., Martodiharjo, S., Andayani, T.M., Hakim, L., 2020. Pengaruh Pelayanan Kefarmasian di Rumah pada Pasien Diabetes Melitus Tipe 2 di Puskesmas Wilayah Kota Yogyakarta. J. Manaj. Dan Pelayanan Farm. J. Manag. Pharm. Pract. 10, 126. https://doi.org/10.22146/jmpf.46240

Susyanty, A.L., Yuniar, Y., J. Herman, M., Prihartini, N., 2020. Kesesuaian Penyelenggaraan Pelayanan Kefarmasian di Puskesmas. Media Penelit. Dan Pengemb. Kesehat. 30, 65-74.

https://doi.org/10.22435/mpk.v30i1.2 062 